\title{
Player and Organization Performance: A Study of First-time Major League Baseball Free Agents
}

\author{
Jeff Barrows*, William Seyfried ${ }^{1}$ \\ ${ }^{1}$ Crummer Graduate School of Business, Winter Park, Florida, United States
}

Copyright $\mathrm{C} 2019$ by authors, all rights reserved. Authors agree that this article remains permanently open access under the terms of the Creative Commons Attribution License 4.0 International License

\begin{abstract}
Since Major League Baseball instituted free agency in 1976, scholars have observed notable increases and decreases in player performance around their eligibility to negotiate as free agents. Beginning with a sample of 305 position players (non-pitchers), this study uses two competing theories of human behavior to explain such changes in player performance between their contract year (year before becoming eligible for free agency) and freeagent year (year after signing a free-agent contract) and explores the impact of player performance on organization revenue in the free-agent year. Based on a comparison of actual and estimated performance in the contract year, 51 players who underperformed were found to have improved performance in their free-agent year and their contributions to organization revenue exceeded their salary. In contrast, 50 players who overperformed in their contract year experienced reduced performance in their free-agent year and their salary exceeded their contributions to organization revenue.
\end{abstract}

Keywords Major League Baseball, Free Agency, Equity Theory, Expectancy Theory, Marginal Revenue Product

\section{Introduction}

"Every free-agent contract in baseball is a gamble." This was the opening sentence in Washington Post sports writer Dave Sheinin's July 14, 2017 column as he reflected on the Boston Red Sox signing of Pablo Sandoval, who became a first-time Major League Baseball (MLB) free agent after the 2014 season. Sheinin characterized the transaction-a five-year, \$95M contract-as a mistake as the Red Sox released Sandoval after two-and-a-half seasons of poor and limited performance. Further exacerbating the situation, the day the Red Sox sent Sandoval packing, they also assumed responsibility for the balance of his free-agent deal-a $\$ 49 \mathrm{M}$ bill. MLB players reach a point in their careers when they can negotiate their services freely with any of the league's 30 organizations. Free agency is lucrative for players as long-term, multi-million dollar contracts have become the norm. Conversely, organizations accept risk when signing a player to a free-agent contract since the financial terms and duration are guaranteed, regardless of player performance. Since the inception of free agency in 1976, scholars have documented significant changes in player performance prior to, and after signing a free-agent contract (for example, see Duchon \& Jago [1]; Ahlstrom et al.[2]; and Estes[3]). These scholars contended that changes in player performance (both positive and negative) were related to the player's opportunity to bargain as free agents. This research assesses the potential impact of free agency on player performance and the impact of player performance on organization performance (revenue) as a result of the player's contributions to team performance (winning percentage) in the year after signing his first freeagent contract.

\subsection{Theoretical Basis for the Study}

The existing academic literature dedicated to MLB free agency has consistently used equity theory and expectancy theory to explain variations in player performance in the year prior to, and the year after signing a free-agent contract. In this study, a broader theoretical perspective offers a new approach in framing the equity theory/expectancy theory debate.

MLB team presidents and general managers are responsible to their ownership groups to assemble a roster of players to form a winning team. Assembling a roster of players may be considered in light of modern portfolio theory (Lampe [4]). While Markowitz [5] envisioned his theory in the context of financial markets, his theory offers guidance on player selection. Markowitz [5] suggested the process of selecting a portfolio should be considered in two stages. The first stage starts with observation and experience and ends with beliefs about the future performance. The second stage starts with beliefs about future performance and ends with the choice of portfolio. Complicating an organization's decision to sign a free 
agent is the fact this opportunity for significant player wealth typically occurs at the intersection of a player's first opportunity for free agency (Isaacs [6]), peak performance (Bradbury[7]) and the average duration of an MLB player's career (Hakes and Turner[8]). Washington National's pitcher Max Scherzer summed up a player's opportunity to bargain as a free agent:

"It's a mental test. Everybody is aware of it. You've worked so hard for so long to put yourself in this position. How many guys make it five years in the big leagues? Not many, so even to give yourself an opportunity to get to free agency is an accomplishment" (Crasnick[9]).

To the chagrin of many MLB organizations, some players have not met performance expectations after signing a free-agent contract (Tylicki[10]). Recognizing the competing interests in the high stakes of free agency, this study incorporates an element of portfolio theory to improve the approach by which organizations navigate free agency. By introducing a model to estimate player performance in the contract year (a player's last year before becoming a free agent) and comparing the estimate to actual performance in the same year, significant variations can be used to establish belief about a player's performance in the free-agent year (year after signing a free-agent contract), offering additional insight into the applications of equity theory and expectancy theory.

\subsection{Literature Review}

\subsubsection{Equity Theory and Expectancy Theory in the Context of MLB Free Agency}

Equity theory and expectancy theory have emerged as the two lenses by which player performance around their period for free agency has been studied. J.S. Adams' equity theory assumes people are motivated by conditions of equity. Adams[11] suggested a person senses inequity when he/she believes that the ratio of his/her perceived outcomes to perceived inputs is different than the same ratio of another; he proposed that individuals reduce or eliminate inequity by altering inputs, such as their performance. Altering (decreasing) performance was first theorized in the context of MLB free agency at its onset in 1976 by Lord and Hohenfeld[12], suggesting players who had not reached the opportunity to negotiate as free agents felt under-compensated compared to their teammates who had. Lord and Hohenfeld[12] found empirical evidence that players restored performance once they signed a free-agent contract and began receiving equitable compensation, consistent with equity theory. This study also draws on equity theory, predicting that players who underperformed in their contract year as compared to estimated performance significantly increased performance in their free-agent year to the point it produced added monetary benefit to the organization.
Expectancy theory is one of the most popular theories of work motivation among organizational scientists (Locke [13]). According to expectancy theory of motivation, individuals make decisions about how much effort they will apply to various tasks based on their subjective beliefs about the probabilities that their effort will lead to better performance and that performance will lead to desired outcomes (Vroom [14]). Harder [15] connected expectancy theory and MLB free agency, theorizing players would increase performance in their contract year to improve their bargaining ability to seek a more lucrative contract. Upon signing a free-agent contract, he found evidence of reduced performance, consistent with an explanation that after signing a free-agent contract, higher performance would no longer be rewarded with additional pay. This study draws on expectancy theory, predicting that players who overperformed in their contract year as compared to estimated performance significantly decreased performance in their free-agent year, such that it produced added monetary benefit to the player.

\subsubsection{Marginal Revenue Products}

Extending the discussion of player performance and its impact on team and organization outcomes, Scully [16], Sommers \& Quinton [17], and Kahn [18] incorporated the idea of marginal revenue products (MRP). In the context of MLB, Scully [16] defined a player's MRP as "the ability or performance that he (player) contributes to the team and the effect of that performance on gate receipts" (Scully [16],p. 916). Once a player's MRP is computed, it can be compared to his salary in a given season; the difference between a player's salary and his MRP is an economic rent in favor of the organization or player.

\subsubsection{Sabermetrics}

Estes [3] was one of the first scholars to stray from individual performance measures, such as batting average and home runs, to composite measures called sabermetrics, which offer a more comprehensive picture of player performance. One of the most widely accepted measures of player performance is on base percentage plus slugging percentage, or OPS. Estes[3] explained that OPS has caught on with the baseball world because it is easy to calculate and is an excellent predictor of runs scored as it credits hitters with getting on base (on base percentage) and the hitters ability to advance runners (slugging percentage).

\section{Objectives}

\subsection{Research Questions and Hypotheses}

Research Question \#1: For first-time free agents, what is the relationship between OPS in the contract year and the free-agent year?

Research Question \#2: For players in their free-agent 
year, what is the relationship between player OPS and economic rent?

The purpose of Research Question \#1 is two-fold. First, while free-agent performance has garnered academic attention, the literature lacks a comprehensive assessment of first-time free agents related to contract-year/free-agentyear performance. Second, to assess performance between the contract and free-agent years, portfolio theory suggests this comparison should begin with an estimate of performance in the contract year as a basis of interpreting any performance deviations in the free-agent year. Research Question \#1 will be assessed using two hypotheses, one for players who underperformed in their contract year and the other for players who overperformed in their contract year. Under and overperformance are defined based on analyzing the distribution of residual values resulting from the difference between player's contract-year OPS and contract-year estimated OPS. H1a is based on the predictions of equity theory and $\mathrm{H} 1 \mathrm{~b}$ is based on the predictions of expectancy theory. The hypotheses associated with Research Question \#1 are as follows:

H1a: Players whose OPS is characterized as underperformance as compared to estimated OPS in their contract year significantly increase OPS in their free-agent year.

H1b: Players whose OPS is characterized as overperformance as compared to estimated OPS in their contract year significantly decrease OPS in their free-agent year.

Scully's [16] desire to show economic loss to the player's due their inability to negotiate as free agents invoked the use of economic rents, which, in this study, will quantify the difference between a player's salary and MRP; a negative economic rent results in financial gain to the organization, as opposed to a positive economic rent, which results in financial gain to the player. Drawing on the predictions of equity theory, H2a will assess whether players who underperformed in their contract year increased performance in the free-agent year to a degree that it produced a negative economic rent. Conversely, $\mathrm{H} 2 \mathrm{~b}$ leverages expectancy theory, testing whether players who overperformed in their contract year decreased performance in their free-agent year to a degree that it produced a positive economic rent. The hypotheses associated with Research Question \#2 are as follows:

H2a: Economic rents are negative for players who underperformed as compared to estimated OPS in their contract year.

$\mathrm{H} 2 \mathrm{~b}$ : Economic rents are positive for players who overperformed as compared to estimated OPS in their contract year.

\section{Methodology}

\subsection{Sample}

This study initially focused on 305 players who signed a first-time, free-agent contract during any year from 1976 through the 2015. The study is limited to non-pitchers only; starting and relief pitchers are excluded due to their irregular play. To qualify as a subject in this research, a player must have: (a) signed and completed the terms of a first-time, free-agent contract of at least one year with the team that signed them to the contract; and (b) using the benchmark established by Estes [3], logged at least 250 plate appearances in five consecutive years: the three years prior to the contract year, the contract year, and the freeagent year.

\subsection{Measures}

\subsubsection{Player Performance}

On-base plus slugging percentage (OPS) is used to measure player performance. In Research Question \#1, contract-year OPS is the independent variable and freeagent-year OPS is the dependent variable. In Research Question \#2, OPS is used to operationalize player performance in MRP calculations. OPS is calculated as show in Equation 1:

$$
O P S=\frac{H+B B+H B P}{A B+B B+H B P+S F}+\frac{H+2 B+(2 * 3 B)+(3 * H R)}{A B}
$$

where $\mathrm{H}=$ hits, $\mathrm{BB}=$ walks, $\mathrm{HBP}=$ hit by pitch, $\mathrm{AB}=$ at bats, $\mathrm{SF}=$ sacrifice flies, $2 \mathrm{~B}=$ doubles, $3 \mathrm{~B}=$ triples, and $\mathrm{HR}=$ home runs.

\subsubsection{Team Performance}

Team performance is a concept used in the two-step MRP calculation necessary to address Research Question \#2. In the MRP calculation, it is important to distinguish between team and organization performance based on how each is measured. Since team winning percentage is typically used in studies involving MRPs (Scully [16]; Sommers \& Quinton [17]; and Kahn [18]), this study also incorporates team winning percentage to measure team performance.

\subsubsection{Organization Performance}

Organization performance is also a concept used in the two-step MRP calculation necessary to address Research Question \#2. Based on the availability of comprehensive organization revenue data in the initial studies related to free agency, authors primarily used gate receipts (average ticket price time's attendance) to measure revenue. Recently, more complete measures of organization revenue have been made available. Accordingly, two revenue models will be run: one to cover all 40 years of this study using only gate receipts and a second-from 1991 through 2016 - using all available revenue sources. For players who qualify for this study during the overlap of these models, an element of robustness is added through comparing results from the two separate revenue models. 


\subsection{Data Sources}

Empirical data required for this study has been mined from several websites. Player data and team winning percentage have been retrieved from baseballreference.com, team attendance has been retrieved from baseballchronology.com and statista.com, average ticket prices have been retrieved from umich.app.box.com, other revenue sources have been retrieved from Forbes.com and Statista.com, team stadium information has been retrieved from ballparksofbaseball.com, and population data has been retrieved from the US Census Bureau. The need for stadium and population data is discussed later in this chapter. Overall, these data tend to be standard measures; most have been cited in the studies discussed in the literature review.

\subsection{Procedures}

\subsubsection{Research Question \#1}

Research Question \#1 is assessed in three steps. First, player performance in the contract year is estimated using a modified version of O'Neill's [19] OPS model as shown in Equation 2:

$$
\begin{aligned}
& O P S_{i, t}=\beta_{0}+\beta_{1} * A G E_{i, t}+\beta_{2} * A G E 2_{i, t} \\
& \quad+\beta_{3} * G A M E S_{i, t}+\beta_{4} * P C T W I N+\beta_{5} * O P S 3 M A_{i, t}
\end{aligned}
$$

where $\mathrm{OPS}_{\mathrm{it}}$ is the estimated OPS of player i in year $\mathrm{t}$, AGE is the player's age, AGE2 is the square of the player's age, GAMES is the number of games played in the contract year, PCTWIN is the winning percentage of the player's team in his contract year, and OPS3MA represents a players average OPS over the three years prior to his contract year (Maxcy, Fort, \& Krautmann [20]).

Second, once OPS is estimated for each player, the difference between actual and estimated OPS will be calculated and the distribution of residuals will yield a standard deviation (SD) that allows the following contractyear performance categories to be established:

Underperformance: Actual OPS $\leq$ estimated OPS -1 SD

Overperformance: Actual OPS $\geq$ estimated OPS +1 SD

No Change: estimated OPS -1 SD < Actual OPS < estimated OPS $+1 \mathrm{SD}$

The third step assesses the test statistic, $\mu_{d}$, which represents the mean difference between contract-year and free-agent-year OPS. Tests will be run separately on the underperformance and overperformance categories; the No Change category is not assessed in this study. As suggested by Estes [21], motivation and performance can be affected when players change teams. Therefore, a binary control variable will be used to denote whether or not a player changed teams between the contract and free-agent years.

\subsubsection{Research Question \#2}

Scully's[16] use of MRPs to assess the contributions of player performance on team and organization performance serve as the statistical approach to address Research Question \#2. This study adapts models from both Scully [16] and Sommers \& Quinton [17] to estimate team winning percentage; the model is shown in Equation 3:

$$
\begin{aligned}
& \text { PCTWIN }_{t}=b_{0}+b_{1} * \text { TOPS }_{t}+b_{2} * \text { TSW }_{t} \\
& +b_{3} * \operatorname{CONT}_{t}+b_{4} * \text { OUT }_{t}+b_{5} * X P A N_{t}
\end{aligned}
$$

where PCTWIN $_{t}$ is the estimated winning percentage of a team in year t, TOPS represents team OPS, TSW is a team's strikeout to walk ratio (to measure the contribution of a team's pitchers), CONT $=1$ if a team won their league championship, division championship, or was less than five games out of division title at the end of a season, 0 otherwise, OUT $=1$ if a team was more than 20 games behind its division leader at the end of a season, 0 otherwise, and XPAN $=1$ if a team was new to MLB as a result of expansion in either of the two years the model was estimated, 0 otherwise. Since 1976, MLB has expanded three times: 1977 (Toronto Blue Jays and Seattle Mariners), 1993 (Colorado Rockies and Florida (now Miami) Marlins), and 1998 (Arizona Diamondbacks and Tampa Bay Devil Rays (now Rays)).

To estimate the impact of team performance on organization revenue, this study amends the Sommers \& Quinton [17] revenue model as shown in Equation 4:

$$
\begin{aligned}
& \text { REVENUE }_{t}=b_{0}+b_{1} * \text { PCTWIN }_{t}+b_{2} * \text { STD }_{t} \\
& +b_{3} * X P A N_{t}+b_{4} * T W O T M+b_{5} * S M S A
\end{aligned}
$$

where REVENUE $E_{t}$ estimates a team's revenue in year $t$ and PCTWIN ${ }_{t}$ is team winning percentage in year t. Sommers \& Quinton[17] incorporated a binary variable to account for the quality and location of a team's stadium (STD). Due to the arbitrary nature of that application, the STD variable here is assigned using an application introduced by Coates \& Humphrey[22], who concluded a new stadium loses its novelty impact in as little as four years. As such, the stadium variable $(\mathrm{STD})=4$ in a year when a team opened a new stadium, with a unit decrease annually down to 0 . $\mathrm{XPAN}=1$ if a team was new to MLB as a result of expansion in either of the two years the model was estimated, 0 otherwise, TWOTM $=1$ if a team shares a home metropolitan area with another team (e.g., New York Yankees and New York Mets), 0 otherwise, and SMSA is a team's Standard Metropolitan Statistical Area (population).

Once the winning percentage and revenue models have been run, it is the coefficients of key terms in each model that allow player MRPs to be computed. In the team winning percentage model, the team OPS coefficient is multiplied by the player's contribution to team OPS (in this case, his contract-year OPS times his proportion of the team's at-bats in the contract year) to establish the player's marginal product component of his MRP. Once the revenue model has been estimated, it is the coefficient of team winning percentage that indicates the marginal revenue of 
a team win and quantifies the marginal revenue component of the MRP. Finally, the player's MRP is found by multiplying the player's marginal product and the marginal revenue. While not elaborated by either the Scully [16] or Sommers \& Quinton [17], the team winning percentage and revenue models were run in two-year increments. For example, Sommers \& Quinton [17] used necessary data from 1976 and 1977 to develop team winning percentage and revenue models to estimate player MRPs for the 1977 season. This study adopts a similar strategy.

\section{Data Analysis and Findings}

\subsection{Research Question \#1}

Because of the cross-sectional nature of the data in this study, Frees \& Jin [23] noted the potential for heteroskedasticity, making Original Least Squares regression inefficient. Using the Breusch-Pagan Test, results confirmed the presence of heteroscedasticity in the proposed estimate model (Equation 2), thus it was reestimated using Weighted Least Squared (Williams [24]) where two independent variables, Age and Age2 were found to be insignificant in estimating contract-year OPS. Accordingly, the estimate model was re-estimated using games played (Games), team winning percentage (WINPCT) and player's average OPS in the three seasons prior to his contract year (OPS3MA). Table 1 below summarizes the descriptive statistics and bivariate correlations for these three variables, along with the dependent variable, contract-year OPS.

Using 0.70 as a benchmark for Pearson's r (Burns and Burns [25]), there is no multi-collinearity present among any other pairs of independent variables. After identifying these three variables, the OPS estimate model implemented in this study was re-estimated using OLS. Table 2 below presents the results of the OLS estimate.

After estimating the model, the distribution of residuals (actual contract-year OPS minus estimated contract-year OPS) was obtained. The residuals were approximately normally distributed with a standard deviation of 0.076 . From the sample of 305 players considered in this study, a total of 51 players were categorized as underperformers and 50 players were categorized as overperformers. For reference, when assessing the ratio of OPS residuals to estimated OPS, the percent change for players categorized as underperformers ranged from $-9.33 \%$ to $-26.73 \%$ indicating their contract-year OPS was between $9.33 \%$ and $26.73 \%$ below what would be expected based on the characteristics included in the OPS estimate model. For players categorized as overperformers, the range was $9.17 \%$ to $37.56 \%$, indicating their contract-year OPS was $9.17 \%$ to $37.56 \%$ above what would be expected based on the characteristics included in the OPS estimate model.

The final step prior to comparing contract-year and freeagent-year performance was to determine whether changing teams between the contract and free-agent year had a significant impact on free-agent-year performance. An analysis of covariance (ANCOVA) was performed on each performance group and revealed team change was insignificant in each case. Since ANCOVA results indicated team change did not have a significant impact on free-agent-year OPS, paired t-tests were used to assess the relationship between contract-year and free-agent-year performance. For the 51 players who were categorized as underperformers in their contract year, results indicated the null hypothesis can be rejected $(\mathrm{t}(50)=-5.433, \mathrm{p}<0.01)$, suggesting players who underperformed in their contract year significantly increased performance in their free-agent year, supporting the predictions of equity theory proposed in H1a. For the 50 players who were categorized as overperformers in their contract year, results showed the null hypothesis can be rejected $(\mathrm{t}(49)=5.641, \mathrm{p}<0.01)$, suggesting that players who overperformed in their contract year significantly decreased performance in their freeagent year. This result supports the predictions of expectancy theory proposed in $\mathrm{H} 2 \mathrm{a}$.

Table 1. Summary Statistics and Correlations for Implemented OPS Estimate Model

\begin{tabular}{|c|c|c|c|c|c|c|}
\hline \multirow{2}{*}{ Variable } & \multicolumn{2}{|c|}{ Descriptive } & \multicolumn{4}{|c|}{ Bivariate Correlations (Pearson's r) } \\
\hline & Mean & SD & 1 & 2 & 3 & 4 \\
\hline 1. OPS & 0.771 & 0.107 & -- & & & \\
\hline 2. OPS3MA & 0.775 & 0.080 & $0.702 * *$ & -- & & \\
\hline 3. Games & 131.046 & 22.815 & $0.234 * *$ & $0.202^{* *}$ & -- & \\
\hline 4. WINPCT & 0.523 & 0.069 & $0.207 * *$ & $0.159 * *$ & $.194 * *$ & -- \\
\hline
\end{tabular}

Table 2. OPS Estimate Regression Results for Implemented Model

\begin{tabular}{|c|c|c|c|}
\hline Variable & Unstandardized Coefficients & t-stat & P-value (one-tail) \\
\hline Intercept & -0.0457 & 0.062 & 0.475 \\
\hline OPS3MA & 0.9014 & 16.159 & 0.000 \\
\hline Games & 0.0004 & 1.961 & 0.025 \\
\hline WINPCT & 0.1303 & 2.022 & 0.022 \\
\hline
\end{tabular}

The model is significant $\left(\mathrm{F}(3,301)=103.727, \mathrm{p}<.01\right.$, adjusted $\left.\mathrm{R}^{2}=.50\right)$ with estimated coefficients as shown. 


\subsection{Research Question \#2}

The first step in addressing Research Question \#2 was to estimate the Team OPS coefficient from the WINPCT model (Equation 3) for each year over the 40-year span of the study where two key observations were noted: (1) the coefficient was insignificant in 1986, 1987, and 1988; and (2) the Team OPS coefficient ranged from a minimum value of 0.23 in 2015 to a maximum value of 0.82 in 1980, offering potential to distort a player's marginal product in any given year. O'Neill [19] suggested, given panel data, estimating such a model using OLS may be inappropriate due to omitted variable bias which occurs because of immeasurable player characteristics in the error term. Accordingly, the team OPS coefficient was estimated using fixed effects regression, an alternative offered by O'Neill [19]. Since MRPs are calculated using gate revenue (19772016) and total revenue (1991-2106), the team OPS coefficients were estimated accordingly.

Next, the Team Winning Percentage variable from the Revenue model (Equation 4) was estimated annually over the duration of the study for both gate and total revenue models. Heteroskedasticity was detected in both sets of models (Gate Revenue: 1977, 1990, 1991, 2003, 2009, and 2010; Total Revenue: 1977, 1990, 2003, 2007-2016) requiring re-estimation using WLS. Additionally, empirical results indicated the estimated coefficients for winning percentage using gate revenue were insignificant in 1995 and 2012-2014 and insignificant for total revenue in 1991, 1992, and 2006.

MRPs for underperformers and overperformers were calculated as previously described. Because of labor strikes in 1981 (108 of 162 games played), 1994 (114 of 162 games played) and 1995 (144 of 162 games played), player salaries in these years were prorated accordingly. MRPs were first calculated using gate revenue from 1977 - 2016 and compared to salary to compute economic rents. Before proceeding with $\mathrm{MRP} /$ salary comparisons for both performance groups and revenue streams, scatterplots of the two variables were visually assessed for the presence of outliners. Since each of the four scatterplots indicated potential outliers, further statistical analyses were necessary to determine whether parametric or nonparametric methods should be used to assess economic rents. This consideration is critical since, computationally, the inflated variance associated with outliers in a parametric test will artificially reduce the test statistic, thus increasing the potential of failing to reject the null hypothesis. In the case of bivariate data, any standardized residual (regression error term divided by standard error of the regression) with an absolute value of 3 or greater should be investigated as a potential outlier (Osborne and Overbay [26]). Using this approach, only one player emerges across both groups as a potential outlier, Pablo Sandoval (categorized as an overperformer; $\mathrm{Z}=-4.37$ for gate revenue and $Z=-3.29$ for total revenue). After signing his free-agent deal with the Red Sox, Sandoval admittedly got complacent: "My career had fallen into an abyss because I was so complacent with things that I had already accomplished. I did not work hard in order to achieve more and to remain at the level of the player that I am and that I can be" (Rodgers [27]). Because Sandoval meets the criteria for inclusion in this study, he was not removed.

In lieu of a parametric paired t-test to assess economic rents for underperformers, this analysis was conducted using Wilcoxon's Signed Rank Test, a non-parametric test more suitable when outliers may be present (Burns \& Burns[25]). For gate revenue, Wilcoxon, $\mathrm{Z}=1.249, \mathrm{p}=$ 0.106 and for total revenue, Wilcoxon, $Z=1.459, p=0.072$. While neither result is significant at the 0.05 level of significance, both results favor the predictions of equity theory proposed in $\mathrm{H} 2 \mathrm{a}$.

For the overperforming group where parametric t-tests were employed, the gate result is significant at $p=0.05$ $(\mathrm{t}(43)=2.112, \mathrm{p}=0.02)$ and the total revenue result is significant at $\mathrm{p}=0.10(\mathrm{t}(31)=1.35, \mathrm{p}=.093)$. Similarly, while only the gate result is significant at $p=0.05$, these results favor the predictions of expectancy theory proposed in $\mathrm{H} 2 \mathrm{~b}$.

\section{Conclusions}

\subsection{Summary}

Consistent with equity theory, 51 players categorized as contract-year underperformers significantly increased performance in their free-agent year, while 50 players categorized as contract-year overperformers significantly decreased free-agent year consistent with expectancy theory. Performance comparisons for each group were assessed controlling for team change between the contract and free-agent year, which was found to be insignificant for both groups. In confirming the predictions of equity and expectancy theories, paired t-tests results for both groups were significant at $\mathrm{p}<0.01$.

Based on a gap in the literature and a recommendation from one MLB executive, this study drew on the predictions of equity and expectancy theories to assess the impact of free-agent-year performance on organization revenue. Given the relationship between contract-year and free-agent-year performance of the underperforming group, the study used equity theory to predict these players would produce an MRP greater than their paid salary in their freeagent year, resulting in a negative economic rent in favor of their organization when considering the difference between salary and MRP. Both results favored the predictions of equity theory ( $p=0.106$ for gate revenue; $p$ $=0.072$ for total revenue). In contrast, reduced performance in the contract year by the group of players who had overperformed in their free-agent year led to positive economic rent in favor of the player as predicted by expectancy theory. This result was found statistically significant for gate revenue $(\mathrm{p}=0.02)$ and favored the 
predictions of expectancy theory for total revenue $(\mathrm{p}=$ 0.093).

The novelty of this study and its empirical results offer valuable information for baseball executives as they navigate free agency. Table 3 below summarizes both performance groups using gate and total revenue and conveys two notable observations. First, a clear disparity when comparing the average salaries of contract-year overperformers and underperformers. Considering both gate and total revenue, contract-year overperformers were paid at least $\$ 2 \mathrm{M}$ more, on average, than underperformers in the first year of their free-agent contracts. While this provides motivation for future free agents to exert maximum effort in their contract year, aligned with portfolio theory, it offers caution to baseball executives that such performance should be carefully considered before establishing the terms of a free-agent contract offer. Second, both gate and total revenue confirm organizations overpaid contract-year overperformers by $\$ 1.2 \mathrm{M}$ in their free-agent year, though organizations enjoyed favorable economic rents when signing contract-year underperformers.

Table 3. Performance Group Free-Agent Year Salary/MRP Summaries

\begin{tabular}{|c|c|c|c|c|}
\hline Category & Revenue & $\begin{array}{c}\text { Sample } \\
\text { Size }\end{array}$ & $\begin{array}{c}\text { Average } \\
\text { Salary }\end{array}$ & $\begin{array}{c}\text { Average } \\
\text { MRP }\end{array}$ \\
\hline Underperform & $\begin{array}{c}\text { Gate }(1977- \\
2016)\end{array}$ & 47 & $\$ 3.13 \mathrm{M}$ & $\$ 3.19 \mathrm{M}$ \\
\hline Underperform & $\begin{array}{c}\text { Total }(1990- \\
2016)\end{array}$ & 32 & $\$ 4.65 \mathrm{M}$ & $\$ 5.32 \mathrm{M}$ \\
\hline Overperform & $\begin{array}{c}\text { Gate }(1977- \\
2016)\end{array}$ & 44 & $\$ 5.13 \mathrm{M}$ & $\$ 3.94 \mathrm{M}$ \\
\hline Overperform & $\begin{array}{c}\text { Total }(1990- \\
2016)\end{array}$ & 32 & $\$ 7.08 \mathrm{M}$ & $\$ 5.87 \mathrm{M}$ \\
\hline
\end{tabular}

\subsection{Limitations}

There are three notable limitations in this study. First, the performance estimate model used in this study produced an adjusted R-Squared value of 0.50 , leaving half of the variance in contract-year performance unexplained and possibly impacting the players categorized as underperformers or overperformers. Second, there were several years in which key coefficients necessary for computing a player's MRP were insignificant, thus eliminating some players from MRP calculations. Third, a lack of comprehensive revenue data from 1976 to 1989 precluded an end-to-end study using what is likely to be the best predictor of organization performance.

\subsection{Future Research}

In response to the noted limitations, efforts to improve the performance estimate model and MRP models is necessary. Improving the performance estimate model is not only important to account for variation in player performance - it also should afford a researcher the opportunity to reduce the tolerance on defining the over and underperformance categories.
While this study was limited to first-time free agents, the approach and methodology offer a baseline to study multiple-time agents. In a study which includes multipletime free agents, researchers must consider how the value of player brand impacts his MRP. Arai et al.[28] defined brand athlete as a persona of a public individual who has developed their own symbolic meaning and value using their name, face, or other brand elements in the market. Business is not the only benefactor-well-branded athletes attain premiums on their salaries, transfer fees, contract monies, and the ability to maintain fan support even when their performance has declined (Gladden \& Funk[29]) and when they are in temporary slumps (Rein et al.[30]; Richelieu \& Pons[31]). More specifically, a veteran player who has established brand value, though is experiencing a decline in performance, may offer a positive component of MRP not captured by this methodology. Such an example was realized in this study. Derek Jeter played his entire 19year career in pinstripes for the New York Yankees. Breaking into the major leagues in 1995, Jeter and the Yankees agreed to contract extensions several times before the Yankees allowed Jeter to become a first-time free agent after the 2010 season. At that point (age 36), Jeter was a World Series champion and 10-time all-star destined for the Baseball Hall of Fame and while his performance was clearly in decline, the Yankees rewarded him with a 4-year, $\$ 60 \mathrm{M}$ free-agent contract. While Jeter did not meet the stated criteria as an outlier in this study, the sizeable variation between his salary and MRP is assumed to be largely attributable to the brand value he offered the Yankees in 2011 and beyond. In future studies including multiple-time free agents, this necessitates quantifying MRP both from a performance and brand perspective to estimate a player's total contribution to an organization's bottom line.

\section{REFERENCES}

[1] Duchon, D., \& Jago, A. G. (1981). Equity and the performance of major league baseball players: an extension of Lord and Hohenfeld, Journal of Applied Psychology, 66(6), 728-732.

[2] Ahlstrom, D., Si, S., \& Kennelly, J. (1999). Free-agent performance in major league baseball: Do teams get what they expect, Journal of Sport Management, 13(3), 181.

[3] Estes, B. C. (2011). Predicting productivity in a complex labor market: a sabermetric assessment of free agency on major league baseball player performance, Business Studies Journal, 3, 23-58.

[4] Lampe, N. (2015). Player contracts and investment diversification, retrieved from $\mathrm{http}: / / \mathrm{sabr}$.org/latest/lampeplayer-contracts-and-investment-diversification.

[5] Markowitz, Harry (1952). Portfolio selection, The Journal of Finance, 7(1), 77-91. 
[6] Isaacs, Noah (2012). Minor league leaderboard context, January 6, retrieved from http://www.fangraphs.com/blogs/ minor-league-leaderboard-context/.

[7] Bradbury, J.C. (2010). How do baseball players age? Baseball Prospectus, January, retrieved from $\mathrm{http}: / /$ www.baseballprospectus.com/article.php?articleid=9 933

[8] Hakes, J. K., \& Turner, C. (2011). Pay, productivity and aging in major league baseball, Journal of Productivity Analysis, 35(1), 61-74.

[9] Crasnick, Jerry (2016). Contending in a contract year: when big bucks and pennant races collide, retrieved from http://www.espn.com/mlb/story/_id/17488183/contendingcontract-year-big-bucks-pennant-races-collide.

[10] Tylicki, Dan (2016). MLB free agency: 50 biggest free-agent busts of all-time, retrieved from http://bleacherreport.com/articles/554808-mlb-free-agency50-biggest-free agent-busts-of-all-time.

[11] Adams, J. S. (1965). Inequity in social exchange. In L. Berkowitz (Ed.), Advances in experimental social psychology: Vol. 2 (pp. 267-299). New York: Academic Press.

[12] Lord, Robert G. \& Hohenfeld, Jeffrey A. (1979). Longitudinal field assessment of equity effects on the performance of major league baseball players, Journal of Applied Psychology, 64(1), 19-26.

[13] Locke, E. A. (1975). Personnel attitudes and motivation, Annual Review of Psychology, 26, 457-480.

[14] Vroom, V H, (1964), Work and motivation. New York: Wiley

[15] Harder, Joseph W. (1991). Equity theory versus expectancy theory: the case of major league baseball free agents, Journal of Applied Psychology, 76(3), 458-464.

[16] Scully, G. W. (1974). Pay and performance in major league baseball. The American Economic Review, 64, 915-930.

[17] Sommers, Paul M. \& Quinton (1982). Pay and performance in major league baseball: the case of the first family of free agents, The Journal of Human Resources, 17(3), 426-36.

[18] Kahn, Lawrence, M. (1993) Free agents, long-term contracts, and compensation in major league baseball: estimates from panel data, The Review of Economics and Statistics, 75(1), 157-164.

[19] O'Neill, H. (2013). Do major league baseball hitters engage in opportunistic behavior? International Advances in Economic Research, 19(3), 215-232.

[20] Maxcy, J. G., Fort, R. D., \& Krautmann, A. C. (2002). The effectiveness of incentive mechanisms in major league baseball, Journal of Sports Economics, 3, 246-255.

[21] Estes, Brent Cullen (2006). Slugger or slacker: a sabermetric assessment of free agency on major league baseball player performance, retrieved from http://diginole.lib.fsu.edu/islan dora/object/fsu:168635

[22] Coates, D. \& Humphreys, B. R. (2005). Novelty effects of new facilities on attendance at professional sporting events, Contemporary Economic Policy, 23(3):436-455.
[23] Frees, E.W. \& Jin, C. (2004). Empirical standards for errors for longitudinal data mixed linear models, Computational Statistics, 19(3), 455-475.

[24] Williams, Richard (2015). Heteroskedasticity, retrieved from https://www3.nd.edu/ rwilliam/stats2/125.pdf

[25] Burns, R. B., \& Burns, R. A. (2008). Business research methods and statistics using SPSS. Los Angeles: SAGE.

[26] Osborne, J.W., \& Overbay, A. (2004). The power of outliers and why researchers should always check for them, Practical Assessment, Research, and Evaluation, 9(6), 1-7.

[27] Rodgers, Joe (2016). Pablo Sandoval, battling weight issues, admits career 'had fallen into an abyss', The Sporting News, retrieved from http://www.sportingnews.co $\mathrm{m} / \mathrm{mlb} /$ news/pablo-sandoval-weight-issues-2017-red-soxcomeback/vv6r8lqe4xlz1xshxn42plzhh

[28] Arai, Akiko, Ko, Yong Jae, \& Ross, Stephen (2014). Branding athletes: exploration and conceptualization of athlete brand image, Sport Management Review, 17, 97-106.

[29] Gladden, J. M., \& Funk, D. C. (2001). Understanding brand loyalty in professional sport: Examining the link between brand associations and brand loyalty, International Journal of Sports Marketing \& Sponsorship, 3, 67-95.

[30] Rein, I., Kotler, P., \& Shields, B. (2006). A sporting chance at branding, Brand Strategy, 30

[31] Richelieu, A., \& Pons, F. (2006). Toronto Maple Leafs vs. Football Club Barcelona: How two legendary sports teams built their brand equity, International Journal of Sports Marketing \& Sponsorship, 7, 231-250. 